\title{
Experimental Investigation of a Hemisphere Contact with a Hard Flat
}

\author{
Pawel PAWLUS, Wieslaw ZELASKO, Andrzej DZIERWA, Slawomir PRUCNAL, Michal WIECZOROWSKI
}

\begin{abstract}
In this paper experimental investigation is presented to study the contact of a deformable hemisphere with a hard flat. Hemispheres were made from steel and copper, but flat from silicon carbide. During contact, deformation of hemisphere was measured. After experiment, plastic contact area of hemisphere was estimated on the basis of surface topography measurement by white light interferometer. The experimental results were compared with the theoretical models, showing good agreement.
\end{abstract}

Keywords: contact; hard flat; hemisphere

\section{INTRODUCTION}

An accurate characterization of contact between rough surfaces is important for analyzing many tribological problems. Therefore contact of rough surfaces is widely studied [1-5]. Statistical models of rough surface contact are usually based on contact behavior of single spherical asperity against a hard flat. Such behavior is then incorporated into the model of contact of many asperities. In normal contact of elastic solids, Hertz theory is used [6]. Abbott and Firestone [7] introduced plastic contact model, in which the area of the contact was supposed to be a simple truncation of deformable sphere by a hard flat.

The pioneering model of elastic contact of rough surfaces was developed by Greenwood and Williamson [8]. In their model, rough flat surface was assumed to be composed of hemispherical asperities. To bridge elastic and plastic contact models, elastic-plastic contact models were introduced. First elastic-plastic contact models were developed on the basis of theoretical considerations. Elastic-plastic contact model of rough surfaces, based on volume conservation was proposed by Chang et al. [9]. Zhao at al. [10] developed elastic-plastic contact model incorporating transition from elastic deformation to fully plastic flow. However this transition is based only on mathematical consideration. Recent models are based on finite element analysis (FEA) of a sphere contact against a hard flat. Kogut and Etsion [11, 12] (KE Model) presented empirical coefficients for relations between dimensionless contact parameters (real contact area, contact load and mean pressure) and interference. Jackson and Green (JG model) performed similar research $[13,14]$ using denser grid of elements than Kogut and Etsion for stick contact conditions. JG model is based on yield stress, contrary to KE model based on hardness. Therefore difference between models exists mainly for fully plastic contact condition. It was found that JG model could be used for ratio between contact radius and sphere radius smaller than 0.412 [15]. Mayuram et al [16, 17] (SM model) used denser grid of elements than Jackson and Green. The result of SM model can be applied for a larger range of plastic deformation than JG model.

There are several models to predict contact load, mean contact pressure and real contact area for hard flat contact with a deformable sphere. Some differences exist between theoretical models and models based on FEA.
Therefore these models should be verified based on experimental research.

Although spherical contact problem has been studied extensively earlier (see for example [6]), experimental research of deformable sphere contact with a hard flat were carried out also lately which is connected presumably with development of measuring equipment In works $[18,19,20]$ the residual contact trace was measured non-in situ. Etsion et al. [18] analysed normal contact between copper spherical specimens (with diameters of $3,5,10$ and $15 \mathrm{~mm}$ ) and rigid flat samples from hardened steels and sapphire. The contact area was measured after unloading using an optical microscope. The maximum normal load was $120 \mathrm{~N}$. Jamari and Schipper $[19,20]$ studied contact of copper and aluminium spheres (with diameters of $6 \mathrm{~mm}$ ) with rigid flat made from $\mathrm{SiC}$ ceramics. After unloading, the real contact area was measured by an optical interference microscope using matching and stitching technique. The maximum possible load applied to this setup was $600 \mathrm{~N}$. In works $[18,19,20]$ the load was applied for 30 seconds and removed.

In few works the contact area was measured in situ. Aymerich and Paul [21] used ultrasonic technique. Steel balls co-acted with steel flat. Diameters of balls were comparatively large $(40-100 \mathrm{~mm})$, normal loads were in the range 2000-10000 N. Ovcharenko et al. [22] measured contact area in-situ through a microscope. Steel and copper spheres were loaded against the hard sapphire flat. The normal load was restricted to 200 N. Diameters of steel and hard spheres were $2.38-4.76 \mathrm{~mm}$, and 5-15 $\mathrm{mm}$, respectively. Similar stand was presented in paper [23]. The normal load was limited to $2 \mathrm{~N}$.

\section{EXPERIMENTAL PROCEDURE}

Experiments were performed using a modified hardness tester. Fig. 1 and Fig. 2 present the research stand. Copper and steel $42 \mathrm{CrMo} 4$ hemispheres with radii of $3.175 \mathrm{~mm}$ were used as deformable samples. Sintered carbides were used as rigid flat specimens. Axial compression tests of softer specimens were performed at different normal loads, up to $1000 \mathrm{~N}$, with load increment of $100 \mathrm{~N}$. During copper specimens testing, in addition, for load smaller than $200 \mathrm{~N}$, load increment was $20 \mathrm{~N}$. Similar to works $[18,19,20]$ load was applied for 30 seconds and removed. Normal force was applied by 
bolted joint of $65 \mathrm{~mm}$ diameter and $0.55 \mathrm{~mm}$ pitch. The point of contact of hemisphere and hard specimen surface was determined using acoustic contact sensor BPT$23 \mathrm{CXW}-1$. Setup of the indentation of a hemisphere against a hard flat allows for measurement of displacement, however normal load was applied by dead weights. Precise measurement of normal load was done using the first version of experimental system, containing load sensor of 0-2500 $\mathrm{N}$ range with accuracy of $\pm 0.1 \mathrm{~N}$. The previous version contained also laser sensor of displacement. In order to minimize deformation of experimental device by increase of its stiffness, both strain gauge and laser displacement sensors were removed in the final version of experimental setup, shown in Fig. 1 , however the normal load was estimated using the previous setup version, for the same weights. The roughness height of flat sample, determined by the $R q$ parameter was $0.2 \mu \mathrm{m}$. Young modulus of silicon carbides was assumed as $350 \mathrm{GPa}$.

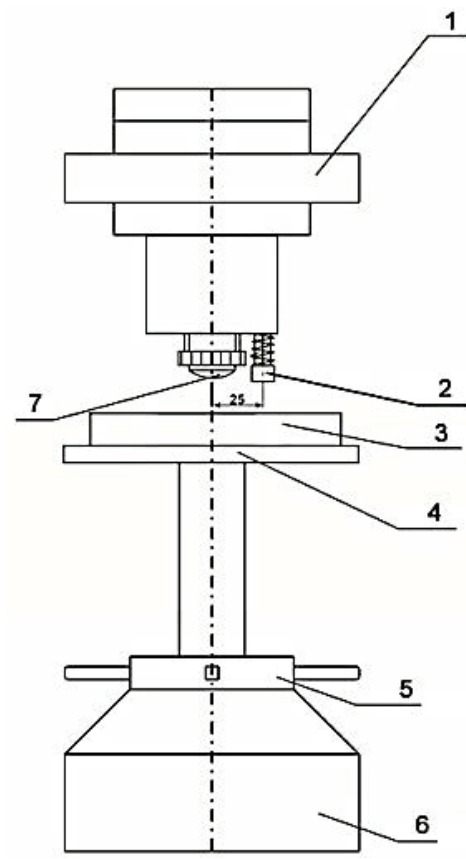

Figure 1 Schematic of the final version of experimental stand ( 1 - place of loading 2 - contact displacement sensor, 3 - hard flat specimen, 4 - table, 5 adjustment of table height, 6 - frame, 7 - hemisphere

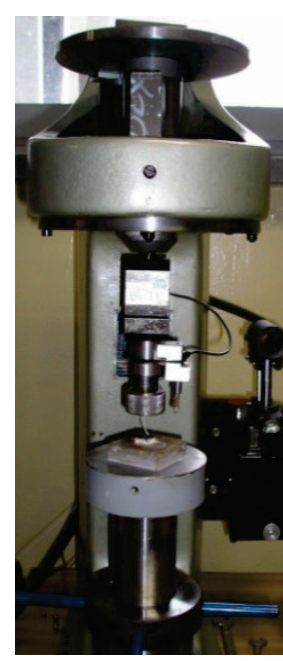

a)

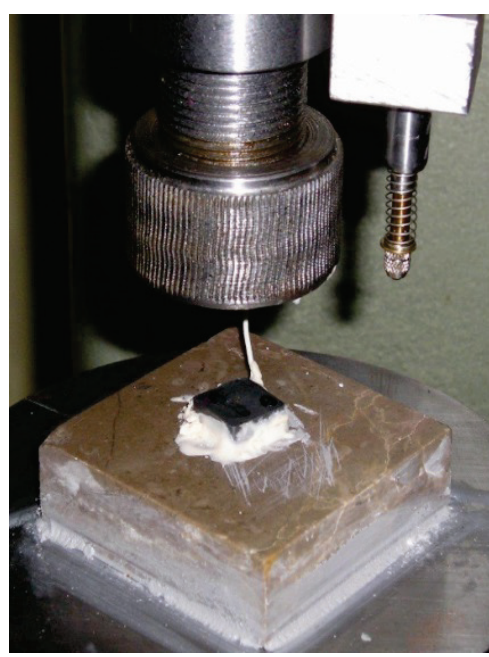

b)
Figure 2 Photos of experimental stand: overall view (a), enlarged detail (b)
Before compression tests, the samples shown in Fig. 3 were cleaned with acetone and dried in air. After tests, plastic contact area was measured by white light interferometer Talysurf CCI Lite. Prior to measurement of the contact area, the hemispheres were again cleaned and dried. Plastic contact area was determined from measuring the contact diameter from plastic deformation trace, using the following formula:

$A_{\mathrm{pl}}=\frac{\pi \cdot b^{2}}{4}$

where $b$ is the plastic contact diameter.

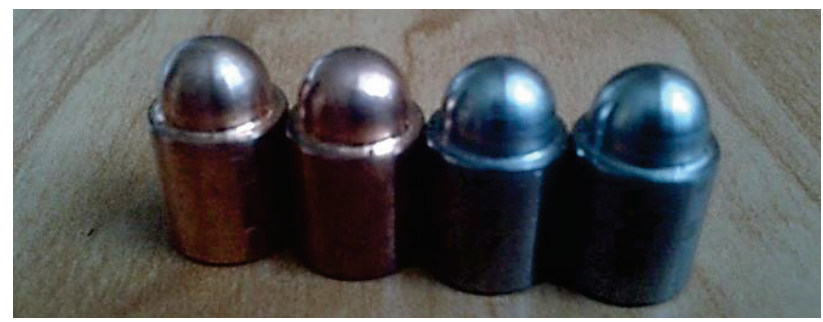

Figure 3 Photos of hemisphere samples from copper and stee

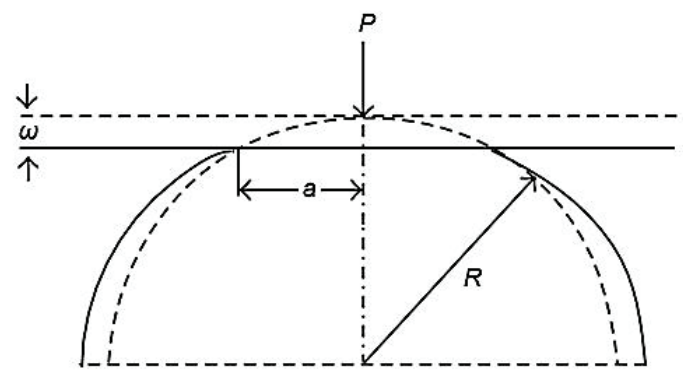

Figure 4 Schematic illustration of a deformable sphere

Plastic interference (see Fig. 4, $2 a=b$ ) was calculated, assuming constant radius of hemisphere during contact experiment, using the following formula:

$\omega=R-\sqrt{R^{2}-\frac{b^{2}}{4}}$,

where $R$ is the radius of hemisphere.

The measurement of plastic contact diameter is sometimes not easy, especially for small deformations. The received surface is not simply truncated, it contains convexities. It is difficult to find where exactly shape differs from a sphere. Therefore the original procedure was used to estimate diameter of plastic contact area. It depends on curvature removal by sphere, this can be done using TalyMap 6 software. It was good to exclude middle detail of deformed surface. It was shown that radius of sphere used for curvature elimination was similar to 3.175 $\mathrm{mm}$. Surfaces after form removal were analyzed. The mean width of received cavity was determined from four cross-sections. Fig. 5 presents the procedure of contact diameter estimation for copper hemisphere for normal load of $620 \mathrm{~N}$, while Fig. 6 for steel hemisphere with normal load of $450 \mathrm{~N}$.

The contact characteristics were compared with theoretical obtained using the JG, KE and SM models. 


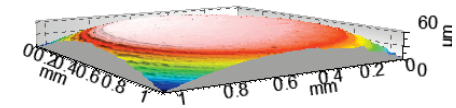

b)

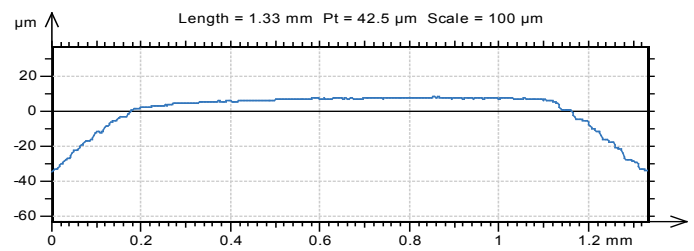

c)

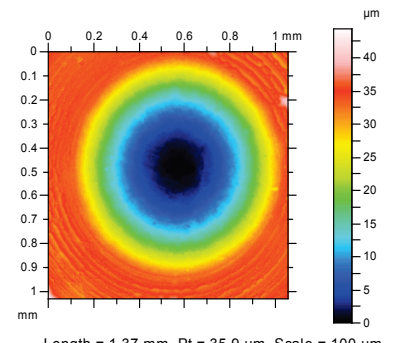

d)

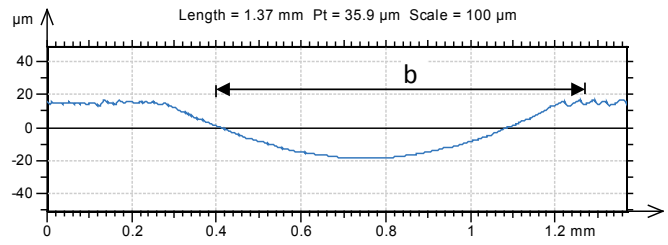

Figure $\mathbf{5}$ Surface of copper hemisphere after normal contact with flat surface from sintered carbides; isometric view (a), profile (b), contour plot after form removal using sphere $(\mathrm{c})$, profile after form removal (d)

a)

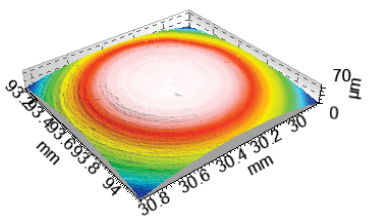

b)

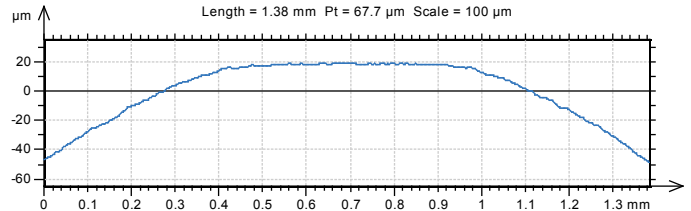

c)

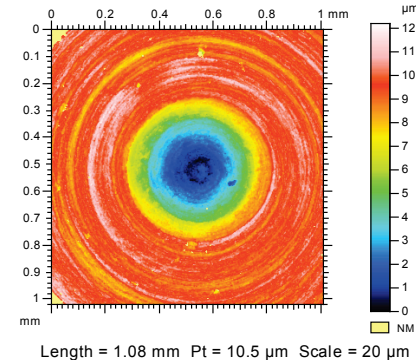

d)

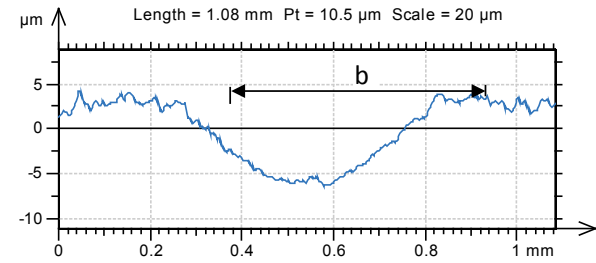

Figure 6 Surface of steel hemisphere after normal contact with flat surface from sintered carbides; isometric view (a), profile (b), contour plot after form removal using sphere $(c)$, profile after form removal $(d)$

\section{RESULTS AND DISCUSSION}

\subsection{Deformations of Copper Hemispheres}

The Vicker's hardness before compression tests was 1.1 GPa (micro hardness, Brivisor KL2 equipment, load
$9.81 \mathrm{~N}$, time $15 \mathrm{~s}$ ). The following material constants were assumed: $E=105 \mathrm{GPa}, v=0.35$. For flat surface from sintered carbides, the following material constants were assumed: $E=450 \mathrm{GPa}, v=0.05$. Equivalent Young modulus $E^{\prime}$ was $94.6 \mathrm{GPa}$.

Because substantial increase of hemispheres hardness was not noticed, copper specimens did not show a strain hardening effect. The critical interference $\omega_{\mathrm{c}}$, at the inception of plastic deformation is given:

$\omega_{\mathrm{c}}=\left(\frac{\pi \cdot K \cdot H}{2 E^{\prime}}\right)^{2} R$,

where $H$ is the hardness of the softer material, and $K$, the hardness coefficient, is related to the Poisson ratio of the softer material by [9] $K=0.454+0.41 \cdot v$.

The critical interference $\omega_{\mathrm{c}}$, calculated according to [9] was $0.3 \mu \mathrm{m}$. Roughness height of copper hemispheres defined by the Ra parameter was $0.2 \mu \mathrm{m}$.

Fig. 7 shows calculated plastic [8] and measured (elastic-plastic) with BPT-23CXW-1 under pressure values of interferences $\omega$ in dependence on normal load $P$. Experimental points were obtained on the basis of at least 5 repetitions. Standard deviation of interference was mostly lower than $1 \mu \mathrm{m}$ (smaller values were obtained for plastic deformation - standard deviation of diameter of plastic contact was usually smaller than $0.015 \mathrm{~mm}$ ). In Fig. 7 expanded uncertainty of interference is presented. One can see from Fig. 7 that substantial deviations between measured and calculated interference started from about $20 \mu \mathrm{m}$ value.

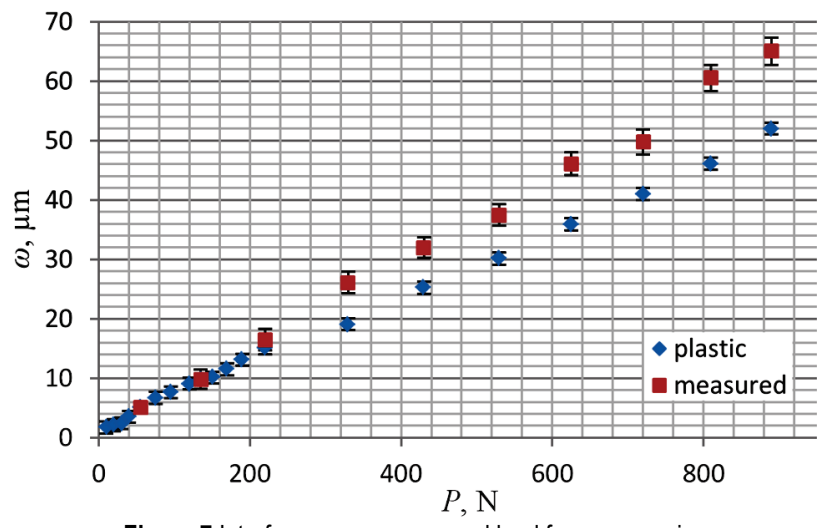

Figure 7 Interference versus normal load for compression of copper hemispheres

The experimental results were compared with those obtained using the JG, KE and SM models (see Fig. 8). Plastic interference (2) was applied, because plastic contact area was calculated after pressure removal. Jamari and Schipper [19] used similar procedure.

For load range of 50-250 $\mathrm{N}$ all the presented dependencies are similar to each other. The highest deviations are smaller than $5 \mu \mathrm{m}$. For normal load higher than $600 \mathrm{~N}$ both calculated and measured displacements are much different from those obtained with the SM model. Plastic interferences are close to those obtained with the JG model and a little higher than using the KE model. 
a)

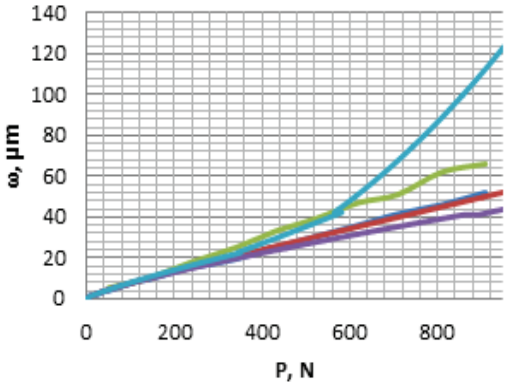

- plastic

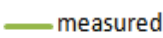

b)

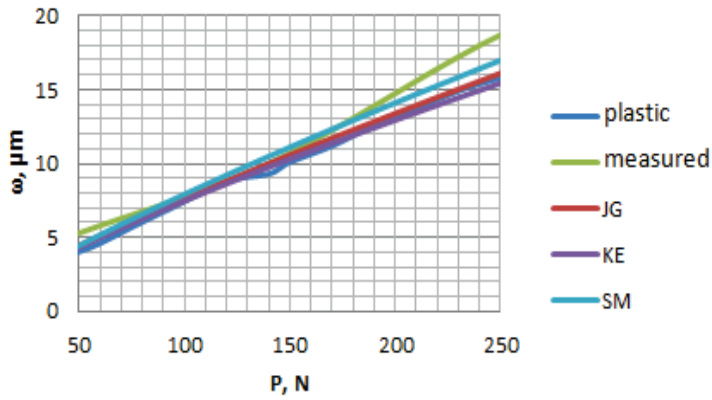

Figure 8 Interference $\omega$ as the function of normal load $P$ of copper hemispheres experimental data (measured, plastic) and results of theoretical models application (KE, JG, SM) for overall range of normal load (a) and for load within the range: $50-250 \mathrm{~N}$

Fig. 9 shows calculated interference as the function of plastic contact area. Similar dependencies obtained with analytical models applications are also presented.

For low interferences, plastic contact area was higher than that obtained with application of analytical models. Jamari and Schipper [19] received similar dependencies considering plastic contact of copper spheres of $3 \mathrm{~mm}$ diameter with a hard flat. The results of plastic area calculation were closer to those obtained after using the SM and JG models than the KE model. However for bigger contact areas considerable differences between calculated interferences and obtained using the SM model aroused. In these cases the results of calculation were similar to those received after using the KE and JG models.

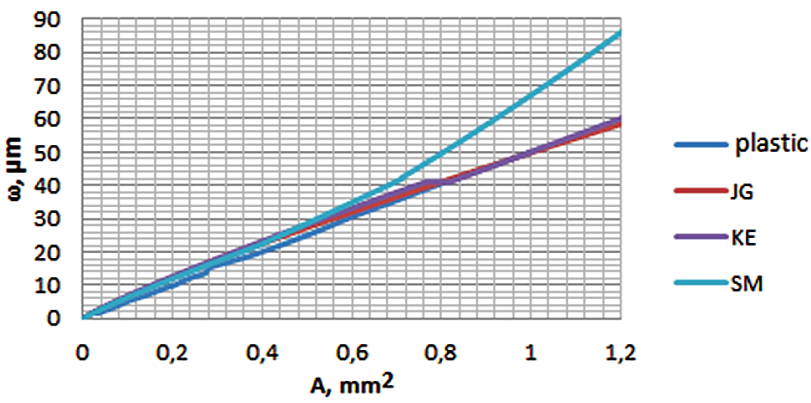

Figure 9 Interference $\omega$ as the function of contact area of copper hemispheres: experimental data (plastic) and results of theoretical models application (KE, JG $\mathrm{SM})$

Fig. 10 presents plastic contact area as the function of normal load, similar dependencies obtained with analytical models are also shown. One can see that for given normal load experimental plastic contact area was close (a little higher) to that obtained using the JG model. Jamari and Schipper [19] obtained similar findings. Plastic contact area was smaller than that obtained using the SM model but higher than the KE model.

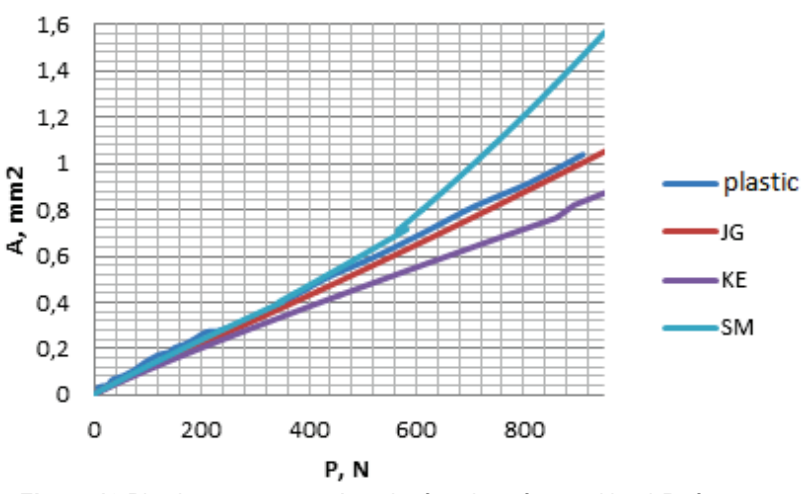

Figure 10 Plastic contact area $A$ as the function of normal load $P$ of copper hemispheres; experimental data (plastic) and results of theoretical models application (KE, JG, SM)

a)

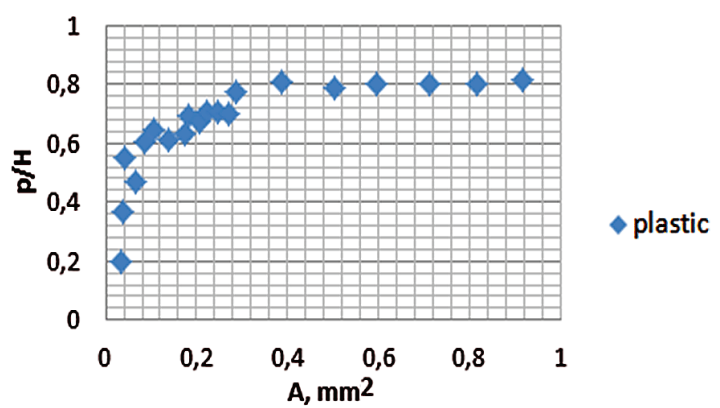

b)

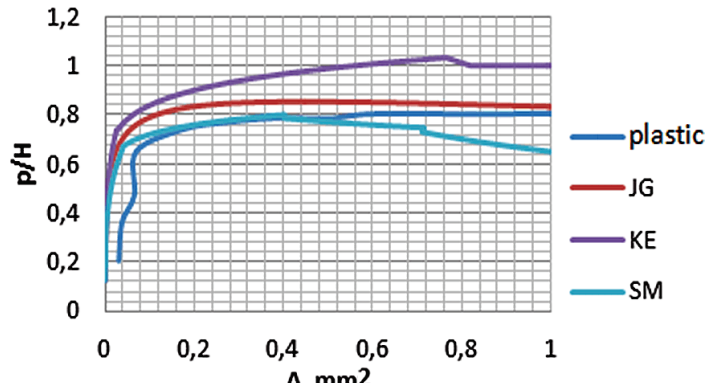

Figure 11 Dimensionless mean contact pressure versus contact area of copper hemispheres; experimental data (a), experimental data (plastic) and results of analytical models (JG, KE, SM) application (b)

Fig. 11a presents dependence between dimensionless average pressure and plastic contact area. The results obtained using analytical models are shown in Fig. 11b. One can see that for plastic contact area larger than 0.2 $\mathrm{mm}^{2}$ mean contact pressure is stabilized at the value of about 0.8 of copper hardness $H$. Jamari and Schipper [19] obtained results in which mean contact pressure remained constant at about $0.75 \mathrm{H}$. These findings are close to those obtained by other researchers, for instance Johnson obtained stable mean constant pressure of about $0.79 \mathrm{H}$ [24], but Chaudhri [25] 0.7H. These results are different to common opinion, based on Tabor work [26] that means contact pressure in fully plastic contact is equal to hardness. However Tabor used a hard indenter against a deformable plane, contrary to the present experiment and works $[19,25]$, where a deformable sphere was pressed against a hard flat - in this case according to Jamari and Schipper [19] the displaced material of the sphere could expand radially in the contact edge. Kogut and Jackson [22] think that in the contact of a hard sphere with a deformable half-space, different models than JG, KE and SM should be used, for instance model described in paper [23]. It seems that the contact area resulted from 
truncation of the sphere by the hard flat - similar to $\mathrm{AF}$ model [2].

It is evident from the analysis of Fig. 11 that dependences between dimensionless mean contact pressure and fully plastic contact area obtained in experimental research for smaller loads are similar to those obtained using the SM and JG models, but for higher loads to the JG model. It is much different from those obtained by the KE model, according to which for fully plastic contact mean contact pressure is equal to the hardness of the softer material. Generally after experimental investigations, the JG contact model should be recommended although qualitative differences between it and experimental results were found - in the JG model contact pressure decreased with the contact area, in experimental research it was constant.

\subsection{Deformations of Steel Hemispheres}

The Vicker's hardness before compression tests was $2.15 \mathrm{GPa}$. The following material constants were assumed: $E=210 \mathrm{GPa}, v=0.3$. Similar to copper hemispheres, increase of hemispheres hardness as the results of compression was not noticed. Critical interference $\omega_{\mathrm{c}}$, calculated according to [9] was $0.55 \mu \mathrm{m}$. Roughness height of steel hemispheres defined by the $R q$ parameter was $0.4 \mu \mathrm{m}$. Roughness height of copper hemispheres was lower due to application of polishing, not changing radius of curvature. Due to technical reasons, polishing was not applied for steel hemispheres. Equivalent Young modulus $E$ ' was $153.8 \mathrm{GPa}$.

Fig. 12 shows calculated plastic and measured (elastic-plastic) values of interferences in dependence of normal load. Similar to copper hemispheres, experimental points were obtained on the basis of at least 5 repetitions.

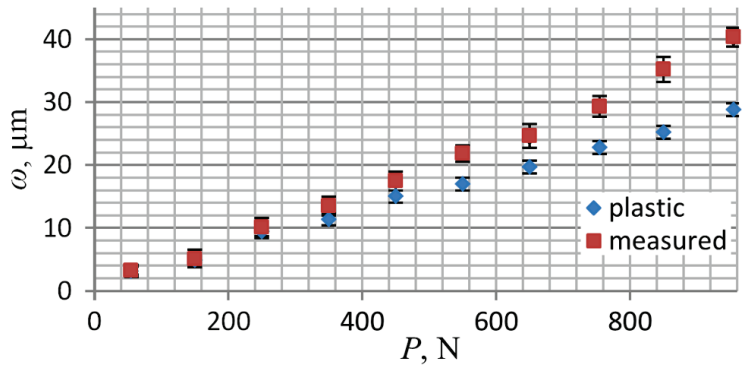

Figure 12 Interference versus normal load for compression of stee hemispheres

For smaller loads the measured and calculated plastic interferences were similar. Measured interferences were a little higher than plastic, which can be the result of elastic content. Larger differences occurred for interferences higher than $15 \mu \mathrm{m}$. It is interesting that similar deviations of interferences were noticed in copper hemispheres compression tests, which suggests possible error in measurement of comparatively high displacements. Repeatability of interference measurement was similar to that of copper hemispheres. Please note that calculations are based not on elastic deformations but on the plastic contact area.

The experimental results were compared with those obtained using the JG, KE and SM models - see Fig. 13.

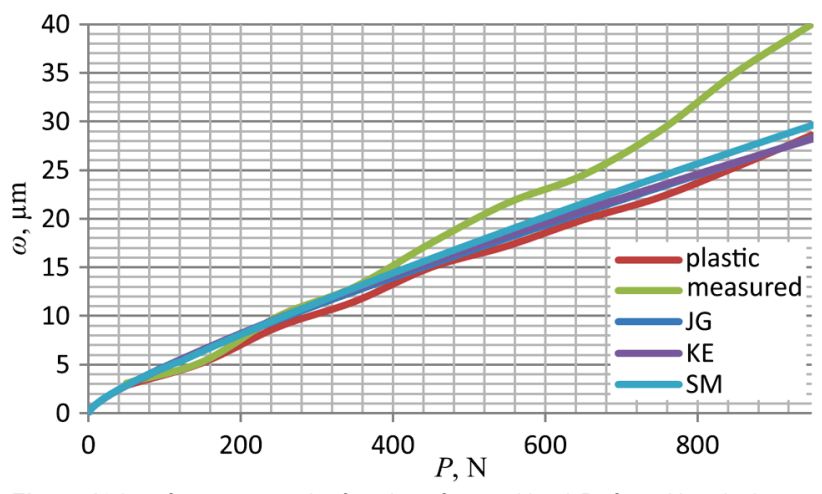

Figure 13 Interference $\omega$ as the function of normal load $P$ of steel hemispheres; experimental data (measured, plastic) and results of theoretical models application (KE, JG, SM)

Since contrary to compression tests of copper hemispheres calculated interferences are not higher than $50 \omega_{\mathrm{c}}$ the results of application of various analytical models are rather similar. Calculated interferences are slightly smaller than those obtained after use of the theoretical models. Lower values of calculated plastic displacements are probably caused by the fact that in the analytical models elastic-plastic deformations (larger than plastic) are considered.

Fig. 14 presents interferences as the function of plastic contact area, the results of analytical models are also presented.

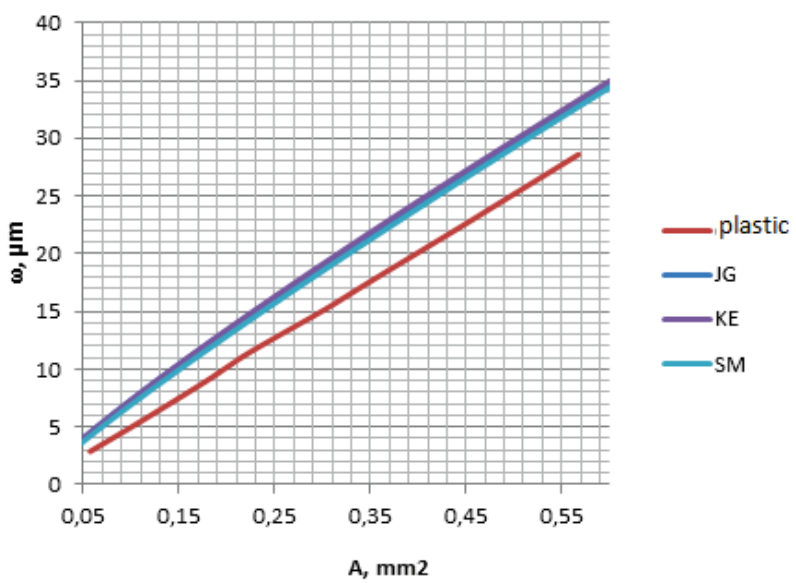

Figure 14 Interference $\omega$ as the function of contact area of steel hemispheres experimental data (plastic) and results of theoretical models application (KE, JG, $\mathrm{SM})$

From the reasons mentioned above, the results of application of analytical models are similar. For the same contact area, calculated interferences based on plastic contact area are smaller than those obtained using analytical models. However differences are smaller than 4 $\mu \mathrm{m}$. Similar results were obtained for small deformations of copper hemispheres - see Fig. 9 and Reference [19].

Fig. 15 presents contact area versus normal load. Not only plastic contact area but also elastic-plastic contact areas obtained using various analytical models are shown. For the same normal load, calculated plastic contact area was slightly larger than those obtained using analytical models. Similar results were obtained for compression tests of copper hemispheres when normal loads were small - see Fig. 10. 


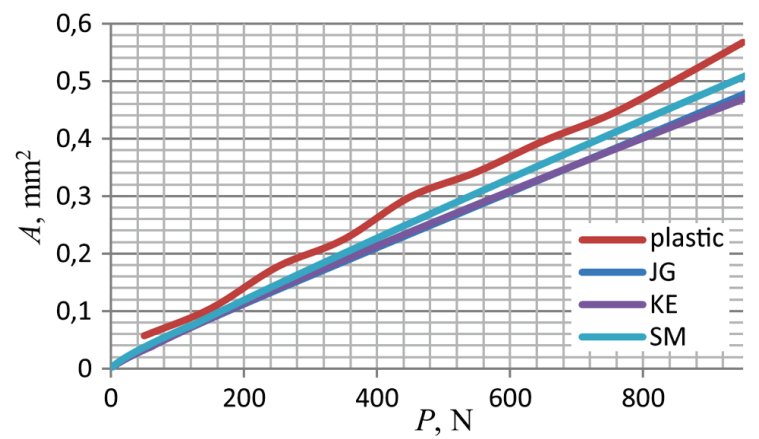

Figure 15 Plastic contact area $A$ as the function of normal load $P$ of steel hemispheres; experimental data (plastic) and results of theoretical models application (KE, JG, SM)

Fig. 16 presents dependence of dimensionless mean average pressure on plastic contact area for compression of steel hemispheres. The results obtained using analytical models are also shown.

a)

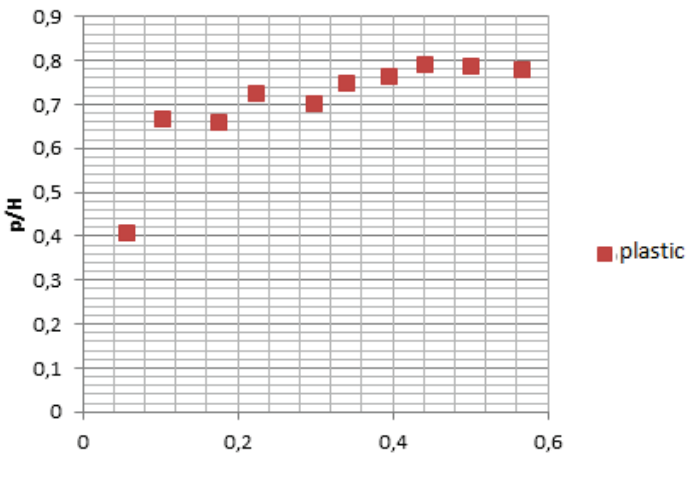

b)

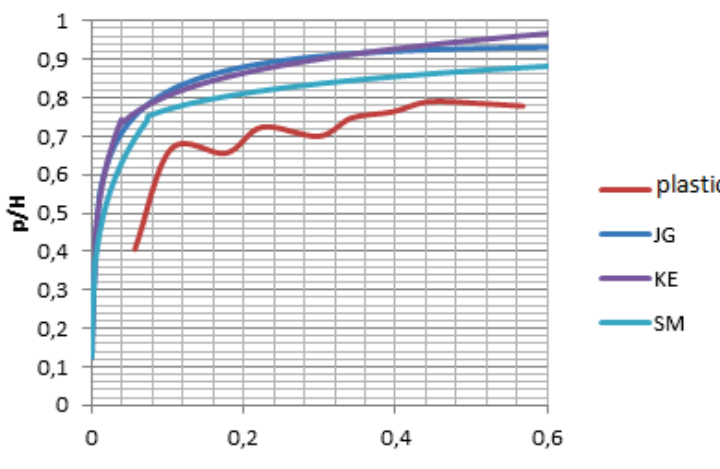

A, $\mathrm{mm} 2$

Figure 16 Dimensionless mean contact pressure versus contact area of steel hemispheres; experimental data (a), experimental data (plastic) and results of analytical models (JG, KE, SM) application (b)

It is evident from the analysis of Fig. 15 that the curve obtained as the result of experimental research is the closest to that resulting from the SM model and then JG model. One can see that in experiment the beginning of plastic deformation was achieved. It seems that similar to copper hemispheres, the value of the ratio $p / H$ stabilized on the 0.8 level. However it is difficult to say that this value will be constant for higher load. The present authors tested steel hemispheres of smaller diameter $(3.175 \mathrm{~mm}$; in that research this ratio was stabilized. The results of those tests are not presented in this paper due to technical problems with obtaining constant values of hemispheres radii. Ovcharenko et al. [22] obtained similar value of the ratio $p / H(0.8)$ during normal loading of steel spheres with different diameters against the sapphire flat.

\section{CONCLUSION}

The experimental research of the normal contact between deformable copper and steel hemispheres and a rigid flat was performed. The results were compared with theoretical models and other experimental research.

The mean contact pressure in fully plastic contact was constant and had a value of $0.8 \mathrm{H}$ both for copper and steel hemispheres. It was confirmed that plastic contact area was truncation of the sphere by the hard flat. The obtained contact characteristic although slightly different from the results of theoretical contact models were the closest to the model developed by Jackson and Green. Measured deformations smaller than $20 \mu \mathrm{m}$ of the hemispheres were similar to calculated plastic interferences.

\section{Acknowledgements}

The authors wish to thank Mr Ryszard Mac and Mr Piotr Koziol for their help in preparing steel samples.

\section{REFERENCES}

[1] Jedynak, R. \& Sulek, M. (2014) Numerical and experimental investigation of plastic interaction between rough surfaces. Arabian Journal for Science and Engineering, 39(5), 4165-4177. https://doi.org/10.1007/s13369-014-1026-6

[2] Buczkowski, R., Kleiber, M. \& Starzynski G. (2014) Normal contact stiffness of fractal rough surfaces. Archives of Mechanics, 66(6), 411-428.

[3] Pawlus, P. \& Zelasko, W. (2012). The importance of sampling interval for rough contact mechanics. Wear, 276277, 121-129. https://doi.org/10.1016/j.wear.2011.12.015

[4] Cohen, D., Kligerman, Y. \& Etsion I. (2008). A model for contact and static friction of nominally flat rough surfaces under full stick contact condition. Journal of Tribology, 130(3), 031401_1-031401 9. https://doi.org/10.1115/1.2908925

[5] Jackson, R. L. \& Green, I. (2011). On the modeling of elastic contact between rough surfaces. Tribology Transactions, 54(2), 300-314. https://doi.org/10.1080/10402004.2010.542277

[6] Johnson, K. L. (1985). Contact mechanics. Cambridge University Press, Cambridge. https://doi.org/10.1017/CB09781139171731

[7] Abbott, E. J. \& Firestone, F. A. (1933). Specifying surface quality - a method based on accurate measurement and comparison. ASME Journal of Mechanical Engineering, 55, 569-572.

[8] Greenwood, J. A. \& Williamson, J. B. P. (1966). Contact of nominally flat surfaces. Proceedings of the Royal Society of London. Series A, Mathematical and Physical Sciences, 295, 300-319. https://doi.org/10.1098/rspa.1966.0242

[9] Chang, W. R., Etsion, I. \& Bogy, D. B. (1987). An elasticplastic model for the contact of rough surfaces. ASME Journal of Tribology, 109(2), 257-263. https://doi.org/10.1115/1.3261348

[10] Zhao, Y., Maietta, D. M. \& Chang, L. (1999). An asperity microcontact model incorporating the transition from elastic deformation to fully plastic flow. ASME Journal of Tribology, 122(1), 86-93. https://doi.org/10.1115/1.555332 
[11] Kogut, L. \& Etsion, I. (2003). A finite element based elastic-plastic model for the contact of rough surfaces. Tribology Transactions, 46(3), 383-390. https://doi.org/10.1080/10402000308982641

[12] Kogut, L. \& Etsion, I. (2002). Elastic-plastic contact analysis of a sphere and a rigid flat. ASME Journal of Applied Mechanics, 69(5), 657-662. https://doi.org/10.1115/1.1490373

[13] Jackson, R. L. \& Green, I. (2005). A finite element study of elasto-plastic hemispherical contact giants a rigid flat. ASME Journal of Tribology, 127(2), 343-354. https://doi.org/10.1115/1.1866166

[14] Jackson, R. L. \& Green, I. (2006). A statistical model of elasto-plastic asperity contact between rough surfaces. Tribology International, 39(9), 906-914. https://doi.org/10.1016/j.triboint.2005.09.001

[15] Quicksall, J. J., Jackson, R. L. \& Green, I. (2004). Elastoplastic hemispherical contact models for various mechanical properties. Proceedings of the Institution of Mechanical Engineers, Part J: Journal of Engineering Tribology, 218(4), 313-322. https://doi.org/10.1243/1350650041762604

[16] Shankar, S. \& Mayuram, M. M. (2008). A finite element based study on the elastic-plastic transition behavior in a hemisphere in contact with a rigid flat. ASME Journal of Tribology, 130,044502_1-044502_6. https://doi.org/10.1115/1.2958081

[17] Megalingam, A. \& Mayuram M. M. (2009). A FEM based multiple asperity contact model. Proceedings of the ASME/STLE International Joint Tribology Conference / Memphis, Tennessee, 2009, 375-377. https://doi.org/10.1115/IJTC2009-15231

[18] Etsion, I., Levinson, O., Halperin, G. \& Varenberg, M. (2005). Experimental investigation of the elastic-plastic contact area and static friction of a sphere on flat. $A S M E$ Journal of Tribology, 127(1), 47-50. https://doi.org/10.1115/1.1843834

[19] Jamari， J. \& Schipper， D. J. (2006). Experimental investigation of fully plastic contact of a sphere against a hard flat. ASME Journal of Tribology, 128(2), 230-235. https://doi.org/10.1115/1.2164470

[20] Jamari, J. \& Schipper, D. J. (2007). Plastic deformation and contact area of an elastic-plastic contact of ellipsoid bodies after unloading. Tribology International, 40(8), 1311-1318. https://doi.org/10.1016/j.triboint.2007.02.015

[21] Aymerich, F. \& Pau, M. (2004). Assessment of nominal contact parameters by means of ultrasonic waves. ASME Journal of Tribology, 126(4), 639-645. https://doi.org/10.1115/1.1760764

[22] Ovcharenko, A., Halperin, G., Verberne, G. \& Etsion, I. (2007). In situ investigation of the contact area in elasticplastic spherical contact during loading-unloading. Tribology Letters, 25(2), 153-160. https://doi.org/10.1007/s11249-006-9164-y

[23] Crick, B. A., Vail, J. R., Persson, B. N. J. \& Sawyer, W. G. (2012). Optical in situ micro tribometer for analysis of real contact area for contact mechanics, adhesion and sliding experiments. Tribology Letters, 45(1), 185-194. https://doi.org/10.1007/s11249-011-9870-y

[24] An experimental determination of the contact stresses between plastically deformed cylinders and spheres. (1968). Engineering Plasticity / Johnson, K. L. // Cambridge, Cambridge University Press, 1968, 341-361.

[25] Chaudhri, M. M. (1987). The plastic deformation of single asperities by hard flats. Proceedings of the Institution of Mechanical Engineers, 158, 1003-1012.

[26] Tabor, D. (1951). The Hardness of Metals. Clarendon Press, Oxford.
[27] Jackson， R. L. \& Kogut, L. (2006). A comparison of flattening and indentation approaches for contact mechanics modeling of single asperity contacts. ASME Journal of Tribology, 128(1), 209-212. https://doi.org/10.1115/1.2114948

[28] Kogut, L. \& Komvopoulos, K. (2004). Analysis of the spherical indentation cycle for elastic-perfectly plastic solids. Journal of Material Research, 19(12), 3641-3653. https://doi.org/10.1557/JMR.2004.0468

Contact information:

\section{Pawel PAWLUS, Professor}

Rzeszow University of Technology

35-959 Rzeszow, Powstancow Warszawy 8 street, Poland

E-mail: ppawlus@prz.edu.pl

Wieslaw ZELASKO, PhD

Group of Technical Schools

37-300 Lezajsk, Mickiewicza 67 street, Poland

E-mail: wzelasko@2be.pl

\section{Andrzej DZIERWA, PhD}

Rzeszow University of Technology

35-959 Rzeszow, Powstancow Warszawy 8 street, Poland

E-mail: adktmiop@prz.edu.pl

\section{Slawomir PRUCNAL, MSc}

Rzeszow University of Technology

35-959 Rzeszow, Powstancow Warszawy 8 street, Poland

E-mail: spktmiop@prz.edu.pl

Michal WIECZOROWSKI, Professor

Poznan University of Technology

60-965 Poznan, Marii Sklodowskiej Curie 5 street, Poland

E-mail: michal.wieczorowski@put.poznan.pl 